\title{
The Cost Effectiveness of Mental Health Treatment in the Lifetime of Older Adults with HIV in New York City: A Markov Approach
}

\author{
Juan J. DelaCruz ${ }^{1}$ (D) Mark Brennan-Ing ${ }^{2}$ (D) Andreas Kakolyris $^{3}$ (D) Omar Martinez $^{4} \mathbb{D}$
}

Accepted: 22 October 2020 / Published online: 9 November 2020

(c) The Author(s) 2020

\begin{abstract}
Background There are noticeable gaps in knowledge regarding the cost and effectiveness of integrated medical and behavioral services for older adults with HIV. Their lifespan is close to the population's level but their quality of life has sharply declined due to depression and substance use. Mental health disorders are widespread among an aging population with HIV. Objective The aim of this study was to build a decision analytic model to evaluate medical interventions with and without mental health treatment using primary data of 139 older adults with HIV and health outcomes from the literature.

Methods We tracked the progression of depression and cumulative deaths among older adults with HIV using a Markov model with 50 annual cycles through three health states. Deterministic and probabilistic sensitivity analyses addressed uncertainty in estimating the parameters and around the model's assumptions.

Results An integrated medical and behavioral care system is cost effective at a willingness to pay of $\$ 50,000$ per QALY compared with medical care only. The incremental cost was $\$ 516,452$ and the incremental effectiveness was 38.8 qualityadjusted life-years (QALY), with an incremental cost-effectiveness ratio of \$13,316 per QALY.

Conclusions Appropriate and efficacious referrals to integrated medical+behavioral services, either in the same facility or connected to their primary care doctor, are instrumental to reverse loses in quality of life and avoid premature death. If mental health is left unattended, HIV would progress, causing declines in quality of life and ultimately triggering premature death. Reliable data on the cost and effectiveness of different types of HIV integrated services are needed.
\end{abstract}

Juan J. DelaCruz

Juan.DelaCruz2@lehman.cuny.edu

Mark Brennan-Ing

mark.ing@hunter.cuny.edu

Andreas Kakolyris

akakolyris01@manhattan.edu

Omar Martinez

tug29454@temple.edu

1 Department of Economics and Business, Lehman College, CUNY, 250 Bedford Park Blvd W, Bronx, NY, USA

2 Brookdale Center for Healthy Aging, Hunter College, CUNY, 2180 Third Avenue, 8th Floor, New York, NY 10035, USA

3 Department of Economics and Finance, Manhattan College, 4513 Manhattan College Parkway, Room DLS 505, Bronx, NY, USA

4 College of Public Health, Temple University, 1301 Cecil B. Moore Ave, Ritter Annex 505, Philadelphia, PA, USA

\section{Key Points for Decision Makers}

Mental health disorders reduce quality of life and accelerate premature death among older adults with HIV.

A medical + behavioral strategy is cost effective, with an incremental cost-effectiveness ratio of $\$ 13,316$ per quality-adjusted life-year.

More evidence-based data on treatment cost and effectiveness is needed to assess the benefits of mental health interventions.

\section{Introduction}

The economics of HIV, aging, and mental health have received poor attention in the literature. HIV is a complex medical challenge as well as an economic and public health issue. The effect of aging on HIV and whether HIV resulted in increased mortality and shortened life expectancy 
is controversial [1]. The well-being of older adults with HIV (OAWH), i.e. individuals 50 years of age and older, is adversely affected by low antiretroviral therapy (ART) adherence, substance use, depression, social isolation, and loneliness. These behavioral disorders cause a decline in quality of life (QoL) and premature death among OAWH compared with other groups [2]. ART has sharply expanded life expectancy for people with HIV [3, 4] but their QoL has worsened due to ART toxicity, aging, comorbidities, polypharmacy, and mental health disorders [5-9]. At most, 50\% of people with HIV under ART suffer from HIV-associated neurocognitive disorders (HAND), such as HIV-associated dementia, and mild neurocognitive disorders defined as lower performance in neurocognitive tests [10-12]. Depression is a chronic and recurrent disease, seldom identified as a factor affecting the outcome of treatment. Episodes of depression increase their frequency over time and their duration is consistent within people with gradual changes over time [13]. Untreated behavioral illnesses are associated with individuals' perception of need for care or to social-structural barriers [14]. Those already linked to HIV treatment can benefit from easy access to suitable mental health care, ranging from costly clinical interventions for severe depression to low-cost options through trained health care workers or group therapy.

A reasonable question is whether achieving lower depression levels with analogous increases in QoL for moderately or severely depressed OAWH is cost effective. Treating people with mild depression reduces the risk of developing major depression over time; thus, addressing depression and substance use is key in reducing the HIV burden [15-17]. Depression is related to low QoL and high medical costs, but psychological interventions can reduce depressive episodes substantially [18]. There is evidence of the benefits of social interaction and engagement on the health and well-being among older adults in successful aging [19]; better care is positively associated with higher survival rates among HIVinfected individuals but is suboptimal when patients have mental health disorders and are substance users [20]. Behavioral care can be grouped as "pharmacotherapy, psychological therapy and the combination of the two" [21]. Some programs are seemingly low-cost, involving weekly phone calls to OAWH from case managers to identify needed resources, but others such as cognitive behavioral therapy are provided at moderate cost [22-24]. Early interventions are advantageous because HIV progression can be triggered if mental health disorders are left unattended [25]. There is narrow evidence on the cost effectiveness regarding outcomes for patients and the delivery of service when combining HIV care and mental health services in different settings [26]. HIV medical care integrated with depression and substance use treatment could be cost saving and cost effective if it identifies specific needs for care [27-29]. Integrated systems are cost effective if mental health is provided in HIV clinics [30]; suitably combining group support psychological treatment with HIV care is cost effective and cost saving in improving the mental health of people with HIV [31].

This paper establishes the cost effectiveness of integrated medical and behavioral treatment among OAWH affected by mental health disorders.

\section{Methods}

\subsection{Target Population}

Estimates show that $70 \%$ of Americans infected with HIV are aged 50 years or older; people of color, as well as the lesbian, gay, bisexual, and transgender (LGBT) community face the greater impact [32]. Primary data $(n=139)$ were collected from a non-random sample of 31 HIV-infected older White/Caucasian patients and 108 HIV-infected older Hispanic patients. Participants were interviewed across HIV clinics and community-based groups in New York City. Our survey was conducted in the summer of 2018 and included questions on socioeconomic, psychosocial, and epidemiological issues. People were screened for eligibility, which included being 50 years of age or older, an HIV diagnosis, and taking ART at least 12 months previous to the survey. Funded by the HIV Intervention Science Training Program for Underrepresented New Investigators (HISTP) [33], our study was granted Institutional Review Board approval for the use of human subjects in research. Informed consent was received from each participant, and participants received assurance of confidentiality and privacy. Participants responding to the Center for Epidemiological Studies-Depression (CES-D) scale with a score of 16 or higher were diagnosed for moderate to severe depression. QoL scores were found using the RAND 36-Item Short Form Health Survey (SF-36) and transformed into Short Form-6 Dimension (SF-6D) estimates to obtain utility measures using the Sheffield licensing software [34-36], which generates a set of preference weights from the general population to produce QALY approximations using a standard gamble health state valuation model (Table 1).

Table 2 shows our utility scores, with a minimum of 0.459 and maximum of 0.876 (range 0.417 ), and with a sample mean of 0.663 (standard deviation [SD] 0.091) and 0.659 (SD 0.076) for White/Caucasian patients, and 0.665 (SD 0.095) for Hispanic patients. The utility scores depicted in Table 2 under standard gamble health state scores were multiplied by life expectancy values for the general population at 79.8 years, and for people with HIV at 71.4 years, generating values for effectiveness of treatment. Thus, these indexes defined effectiveness as effMildDepress at 48.64 QALYs for mild depression, and as effSevereDepress at 43.26 QALYs 
Table 1 Cost-effectiveness inputs (Markov)

\begin{tabular}{|c|c|c|c|c|}
\hline Variable & Value & Description & Distribution & References \\
\hline tCycles & 50 & Number of cycles (years) & & Estimated \\
\hline cART1 & $\$ 24,881$ & Cost of HIV medical treatment & $\begin{array}{l}\text { Log-normal distribution (mean } \$ 24,881 \text {; } \\
\text { SD } \$ 14,219 ; 95 \% \text { CI } \$ 7621-\$ 61,234)\end{array}$ & Gebo et al., 2010 [53] \\
\hline cMental & $\$ 45,630$ & Cost of having behavioral treatment & $\begin{array}{l}\text { Log-normal distribution (mean } \\
\$ 45,630 ; \text { SD } \$ 26,075 ; 95 \% \text { CI } \\
\$ 13,976-\$ 112,300)\end{array}$ & Weaver et al., 2009 [55] \\
\hline cMental2 & 0 & Cost of not having behavioral treatment & & Estimate \\
\hline pLowRiskDepress & 0.588 & Probability of low risk of depression & $\begin{array}{l}\text { Beta distribution (mean 0.588; SD 0.06; } \\
\text { 95\% CI 0.468-0.703) }\end{array}$ & Bhatia and Munjal, 2014 [46] \\
\hline pHighRiskDepress & 0.874 & Probability of high risk of depression & $\begin{array}{l}\text { Beta distribution (mean 0.874; SD 0.05; } \\
\text { 95\% CI 0.761-0.954) }\end{array}$ & Survey, 2018 \\
\hline pDieAIDSDep & 0.03 & $\begin{array}{l}\text { Probability of dying of HIV and depres- } \\
\text { sion }\end{array}$ & $\begin{array}{l}\text { Beta distribution (mean 0.03; SD 0.005; } \\
\text { 95\% CI 0.02-0.04) }\end{array}$ & Estimated \\
\hline pImprove & 0.700 & $\begin{array}{l}\text { Probability of improving after the } \\
\text { intervention }\end{array}$ & $\begin{array}{l}\text { Beta distribution (mean 0.700; SD 0.08; } \\
\text { 95\% CI 0.53-0.84) }\end{array}$ & Keller et al., 1992 [53] \\
\hline AgeStart & 50 & Starting age of the OAWH & & Estimated \\
\hline pDieAIDS & 0.014 & Probability of dying of HIV & & CDC, 2019 [52] \\
\hline eHisp & 0.665 & Quality of life for Hispanic subjects & & Survey, 2018 \\
\hline eWhite & 0.659 & $\begin{array}{l}\text { Quality of life for White/Caucasian } \\
\text { subjects }\end{array}$ & & Survey, 2018 \\
\hline eSample & 0.663 & Quality of life for the sample & & Survey, 2018 \\
\hline lifePOP & 79.7 & $\begin{array}{l}\text { Life expectancy for the general popula- } \\
\text { tion }\end{array}$ & & The World Bank, 2020 [38] \\
\hline lifeHIV & 71.4 & Life expectancy for people with HIV & & Samji et al., 2013 [37] \\
\hline effMildDepress & 48.64 & QALY for healthy OAWH & & Estimated \\
\hline effSevereDepress & 43.26 & QALY for depressed OAWH & & Estimated \\
\hline AgeCurrent & & $50($ age start $)+$ stage & & Estimated \\
\hline $\begin{array}{l}\text { TblDeathBack- } \\
\text { ground }\end{array}$ & & Life Table & & Arias and $\mathrm{Xu}[54]$ \\
\hline
\end{tabular}

$O A W H$ older adults with HIV, $Q A L Y$ quality-adjusted life-year, $S D$ standard deviation, $C I$ confidence interval, $C D C$ Centers for Disease Control and Prevention

Table 2 Depression, utility, and quality-of-life scores with eight dimensions of health

\begin{tabular}{lccc}
\hline & $\begin{array}{l}\text { Sample } \\
\text { Mean (SD) }\end{array}$ & $\begin{array}{l}\text { White subjects } \\
\text { Mean (SD) }\end{array}$ & $\begin{array}{l}\text { Hispanic subjects } \\
\text { Mean (SD) }\end{array}$ \\
\hline CES-D & $15.41(6.01)$ & $16.23(4.59)$ & $15.16(6.37)$ \\
QoL score $(\mathrm{O} \leq \mathrm{Q}$ QL $\leq 1)$ & $0.62(0.11)$ & $0.64(0.09)$ & $0.61(0.11)$ \\
Standard gamble health state score & $0.663(0.091)$ & $0.659(0.076)$ & $0.665(0.095)$ \\
Ordinal health state score & $0.679(0.114)$ & $0.684(0.109)$ & $0.679(0.116)$ \\
SF-36 Eight Dimensions of Health & & & \\
Physical Functioning & $0.70(0.25)$ & $0.77(0.22)$ & $0.68(0.26)$ \\
Role functioning/physical & $0.53(0.44)$ & $0.56(0.43)$ & $0.52(0.44)$ \\
Role functioning/emotional & $0.56(0.44)$ & $0.57(0.46)$ & $0.55(0.44)$ \\
Energy/fatigue & $0.53(0.21)$ & $0.49(0.16)$ & $0.54(0.23)$ \\
Emotional well-being & $0.61(0.23)$ & $0.59(0.17)$ & $0.62(0.25)$ \\
Social functioning & $0.63(0.29)$ & $0.65(0.28)$ & $0.62(0.30)$ \\
Pain & $0.61(0.29)$ & $0.73(0.21)$ & $0.58(0.30)$ \\
General health & $0.58(0.24)$ & $0.64(0.20)$ & $0.57(0.25)$ \\
\hline
\end{tabular}

$S D$ standard deviation, $C E S-D$ Center for Epidemiological Studies-Depression, $Q o L$ quality of life, $S F-36$ Short-Form 36 
for severe depression. Similar values were computed for Hispanic and White patients [3, 37, 38].

Our subjects included $84.2 \%$ males, and $76 \%$ lived alone. The mean age was 59.1 years (SD 6.6). Only $17 \%$ of subjects reported some employment status, $67.4 \%$ had some college education, and $23.8 \%$ were undocumented immigrants. Our participants experienced high levels of ART adherence, i.e. 95.2\% (standard error [SE] 1.9\%) in the sample, 96.6\% (SE $3.4 \%$ ) in White subjects, and 94.8\% (SE 2.2\%) in Hispanic subjects. The proportion of viral suppression was $95.2 \%$ (SE $1.9 \%$ ) in the sample, $100 \%$ for White/Caucasian subjects, and $93.8 \%$ (SE 2.4\%) for Hispanic subjects; OAWH achieved ART adherence, with the corresponding viral load and CD4 $\mathrm{T}$ cells at clinically acceptable levels.

\subsection{Decision Model}

The Markov model was based on a cohort simulation size of 1 , which is split into fractions as it spreads through the model cycle-by-cycle. We obtained a weighted average of all patient pathways based on the assigned probabilities, with costs and utilities accumulating along the path via the weighted average calculations to obtain the average cost and effectiveness per patient. We estimated the cumulative cost and effectiveness of behavioral care for OAWH over a finite time frame using singular health states.

Figure 1 shows the state transition diagram, which was the base upon which to build state rewards using Markov cycle trees in TreeAge Pro [39]. We probed the relative health outcomes of two strategies: medical care only (medical) compared with medical plus behavioral care (medical + behavioral), assuming integrated systems where doctors referred patients to suitable mental health services, with follow-up over time. Integrated care for OAWH provides ART concurrent with mental health treatment to address several forms of depression and substance use, conditions that were highly prevalent in our sample. This combined intervention can be delivered in a single facility, in multiple places, or can be facilitated by a case manager or social worker. In each setting, we need to consider cost-effectiveness issues as well as potential fragmentation and deficiencies in the coordination of services [26].

We simulated the progression of depression and cumulative deaths for 50 years to follow our cohort throughout their lifetime horizon, using mutually exclusive and exhaustive health states, with movements across health states determined by transition probabilities. Our model included cohort analysis with half-cycle corrections to reduce the impact of overestimates [40]. Every cycle carries the costs and effectiveness, with a probability of developing ' $n o$ to mild depression', meaning that OAWH adhere to ART, stay virally suppressed throughout the cycles, and show, at most, mild depression or substance

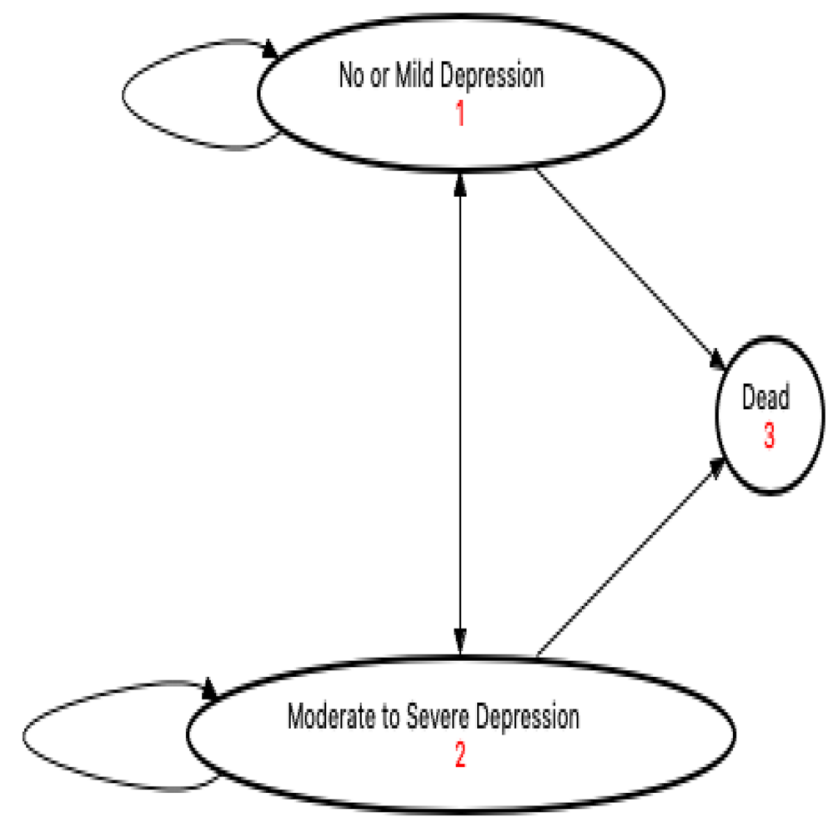

Fig. 1 State transition diagram of strategies: the circles represent the health states and the arrows represent the transition between different health states. Individuals can stay in their health states as well as transit back and forth between health states. Death is the terminal node and bears neither cost nor efectiveness rewards

use. The risk of feeling 'moderate to severe depression' represents a person who may adhere to ART, is virally suppressed, and experiences at least moderate depression being referred and followed-up to behavioral care. The criteria for depression was established using the CES-D20 survey, in which a participant with a score of 16 points or more is considered moderately to severely depressed $[41,42]$. The probability of 'dead' in all health states was caused by AIDS or severe mental health conditions and mortality caused by factors different from those under study $[43,44]$.

Figure 2 depicts the full decision analytic model. At cycle 0 , all individuals enjoy relatively good QoL (no to mild depression) and remain in good health (StaysMild), are diagnosed with depression (depressive), or can die from AIDS-related conditions (DieAIDS). OAWH in the moderate to severe depression state experience low QoL but are referred to behavioral care, then improve and return to the no to mild depression state. If mental health treatment fails, the OAWH stays depressed (StayDep) and the likelihood of early death increases (DieAIDS + Depress). Background death occurs in all health states. The cohort moves between health states as time progresses, and then splits among states before each cycle is given a probability. The transition subtrees are associated with health states occurring within a cycle until the terminal node is reached; the cohort then returns to a health state for the next cycle via the jump state. 


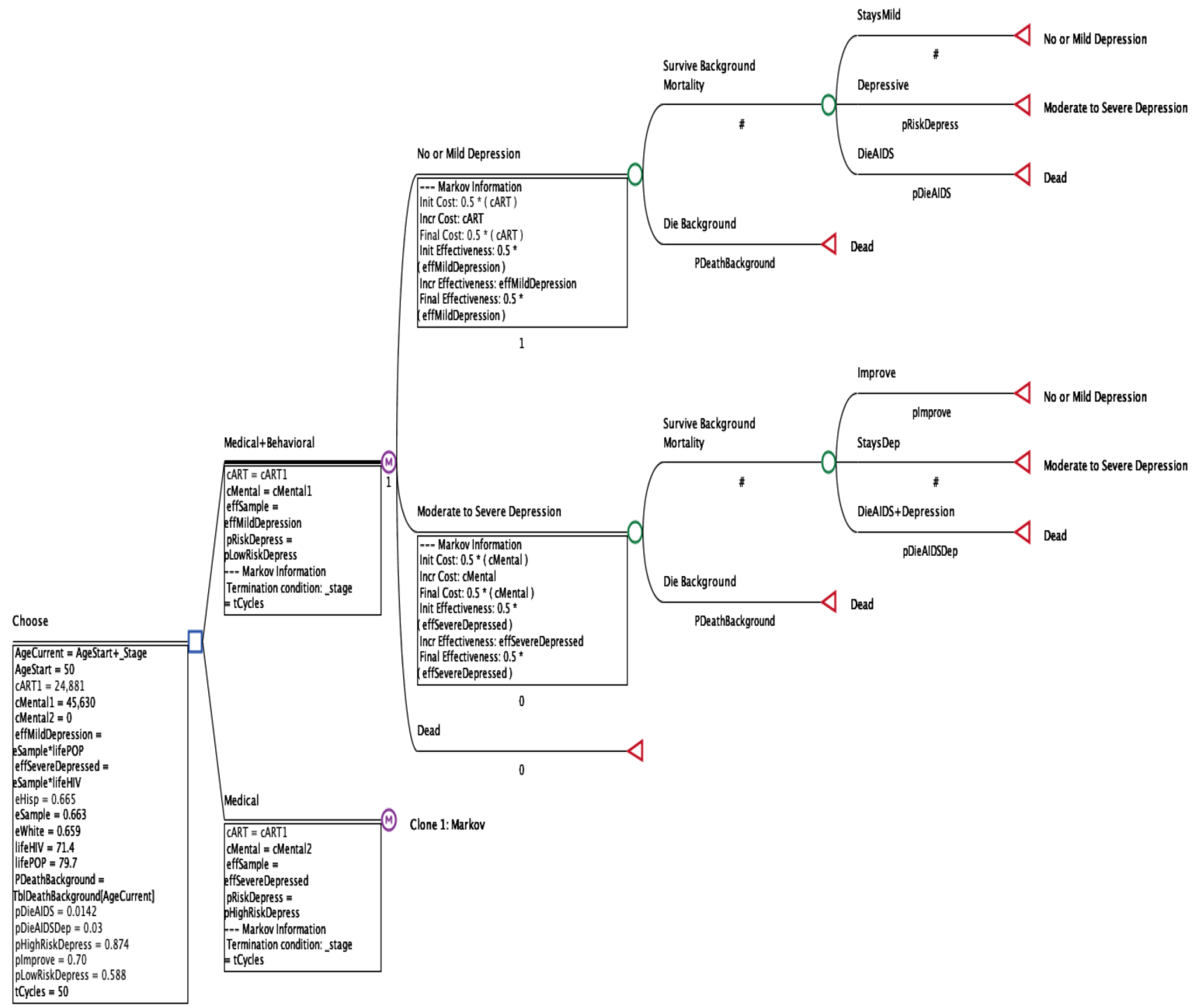

Fig. 2 Decision analytic model (Markov tree diagram). TreeAge model for decision analysis with two strategies, three health states, and transition probabilities, representing events within a cycle rather than all scenarios over the entire time horizon

The strategies of both the medical and medical + behavioral cohorts follow the same pattern.

\subsection{Cost, Effectiveness, and Probabilities}

Table 1 describes the economic evaluation inputs used in the Markov model health states [45]. We compared two groups of OAWH, one with a low risk of depression of $58.8 \%$ [46] and those who experienced a high risk of depression of $87.4 \%$. Given the probability of improving (pImprove) from the intervention, we argue that an initial low level of moderate or severe depression among OAWH maximizes health and produces the largest number of QALYs for the expenditure. Our goal is to compute cost and effectiveness derived from mental health care. The rate of dying from
AIDS-related conditions (pDieAIDS) in the no to mild depression group [47-50] was $1.42 \%$, computed from people with HIV who died in 2017 divided by the estimated prevalence [51]. Because OAWH are at higher risk from comorbidities and other factors [52], we reasonably assumed the likelihood of dying from AIDS-related and depressionrelated conditions (pDieAIDSDep) while being in the moderate to severe depression state was 3\%. Keller et al. [53] suggested that after consistent and supervised mental health treatment, at most $70 \%$ of patients recover from depression within the year; this value served as the probability of recovering from depression during the cycle (pImprove). Background mortality was built using the 2017 US Life Tables from the Centers for Disease Control and Prevention [54] for 
a period of 50 years (ages 50-100 years) to account for the lifetime horizon of our cohort.

The cost-effectiveness analysis (CEA) used a healthcare perspective because the cost of reducing mental health disorders is carried by a third-party or by patients [55]. There is limited information regarding the treatment cost, and data are often retrieved from the current literature. The average annual cost of medical treatment for people with HIV (cART1 in the no to mild depression state) was $\$ 24,881$ per year in 2006 prices inflated to 2019 , based on a large-scale purchaser of services providing large discounts [56]. These values included the per unit cost of clinic visits (inpatient, outpatient, and emergency) multiplied by its frequency, as well as blood tests, HIV medications, and opportunistic infection drugs over 1 year [57]. Weaver et al. [58] used a health sector budget view to determine the cost of HIV treatment with integrated care for chronic mental illness and substance abuse disorders among HIV-infected individuals (cMentall for the moderate to severe depression state). The cost was $\$ 45,630$ per year in 2009 prices inflated to 2019 , comprising medical, mental health, and substance abuse visits to inpatient, outpatient, and correctional facilities, and cost of medications among eight types of services, and used Medicare payments for monetary values; this calculation excluded patient and family costs. The willingness to pay (WTP) or "the basis of the Value of a Statistical Life and other measures used for calculating the economic value of morbidity and mortality improvements" [59] was computed using a scalar for the 2018 gross domestic product and was set at $\$ 50,000$ per QALY [60-62]. We inflated the cost of HIV and mental health treatment to 2019 US dollar values to account for inflation, based on the Consumer Price Index capturing changes in the prices of goods and services purchased by urban households, not seasonally adjusted [63]. We applied a 3\% discount rate for cost and effectiveness occurring in the future.

\section{Results}

Based on a Markov analysis, the medical + behavioral strategy is cost effective compared with medical-only treatment, with a WTP at $\$ 50,000$ per QALY. Table 3a reports the cost-effectiveness rankings for the two strategies, with an incremental cost of $\$ 518,971$, an incremental effectiveness of 38.8 QALYs, and an incremental cost-effectiveness ratio (ICER) of $\$ 13,380$ per QALY. As originally expected, the net monetary benefits (NMBs) are higher for the medi$\mathrm{cal}+$ behavioral intervention compared with the medicalonly intervention.

\subsection{Survivorship and Cumulative Death}

The Markov probability analysis graph shown in Fig. 3 shows that as the cohort moves across the cycles, the survival curve for no to mild depression lies above the moderate to severe depression curve. The initial depression rate was fairly high in our sample, but our model assumes that moderate or severe depression was addressed in a timely and successful manner by targeted referrals to mental health services. The whole cohort starts at stage 0 of the Markov simulation but splits in the transition subtrees, where 39.6\% of the cohort show signs of no to mild depression but $58.5 \%$ experience moderate to severe depression and $1.9 \%$ die from causes unrelated to HIV/AIDS or depression in year 1. We presumed that OAWH with major depression were referred to behavioral care, with a $70 \%$ chance of improving within the first year. In year 2, because $70 \%$ of those patients recovered from depression and returned to the no
Table 3 Cost-effectiveness rankings

\begin{tabular}{|c|c|c|c|c|c|c|}
\hline Strategy & Cost & $\Delta$ Cost & Eff $^{\mathrm{a}}$ & $\Delta \mathrm{Eff}^{\mathrm{b}, \mathrm{c}}$ & $\mathrm{ICER}^{\mathrm{c}}$ & NMB \\
\hline \multicolumn{7}{|l|}{ (a) Deterministic } \\
\hline Medical & $\$ 243,164$ & & 1080.8 & & & $\$ 53,796,665$ \\
\hline $\begin{array}{l}\text { Medical + behavioral } \\
\text { (b) Probabilistic }\end{array}$ & $\$ 759,615$ & $\$ 516,452$ & 1119.6 & 38.8 & $\$ 13,316$ & $\$ 55,219,527$ \\
\hline Medical & $\$ 280,052$ & & 1080.8 & & & $\$ 53,759,777$ \\
\hline Medical + behavioral & $\$ 886,145$ & $\$ 606,093$ & 1107.2 & 26.4 & $\$ 22,946$ & $\$ 54,474,362$ \\
\hline \multicolumn{7}{|c|}{$\begin{array}{l}\Delta \text { Cost represents the difference between the less expensive intervention (medical care only) and the more } \\
\text { expensive intervention (medical + behavioral care) }\end{array}$} \\
\hline \multicolumn{7}{|c|}{$\begin{array}{l}\triangle \text { Effectiveness represents the difference in effectiveness between our two strategies, ICER represents the } \\
\text { ratio of incremental cost divided by the incremental effectiveness, } N M B \text { represents the monetary value of } \\
\text { a program given the WTP, Eff effectiveness, ICER incremental cost-effectiveness ratio, } N M B \text { net monetary } \\
\text { benefit, } Q A L Y s \text { quality-adjusted life-years, WTP willingness to pay }\end{array}$} \\
\hline \multicolumn{7}{|l|}{${ }^{\mathrm{a}}$ Measured in QALYs } \\
\hline \multicolumn{7}{|c|}{${ }^{\mathrm{b}}$ Incremental effectiveness } \\
\hline \multicolumn{7}{|c|}{${ }^{\mathrm{c}}$ Measured in US dollars per QALY } \\
\hline
\end{tabular}


Fig. 3 Markov probability analysis (medical + behavioral strategy). The survival curve for no to mild depression lies above the moderate to severe depression curve. Cumulative mortality rises throughout the lifetime of the simulation

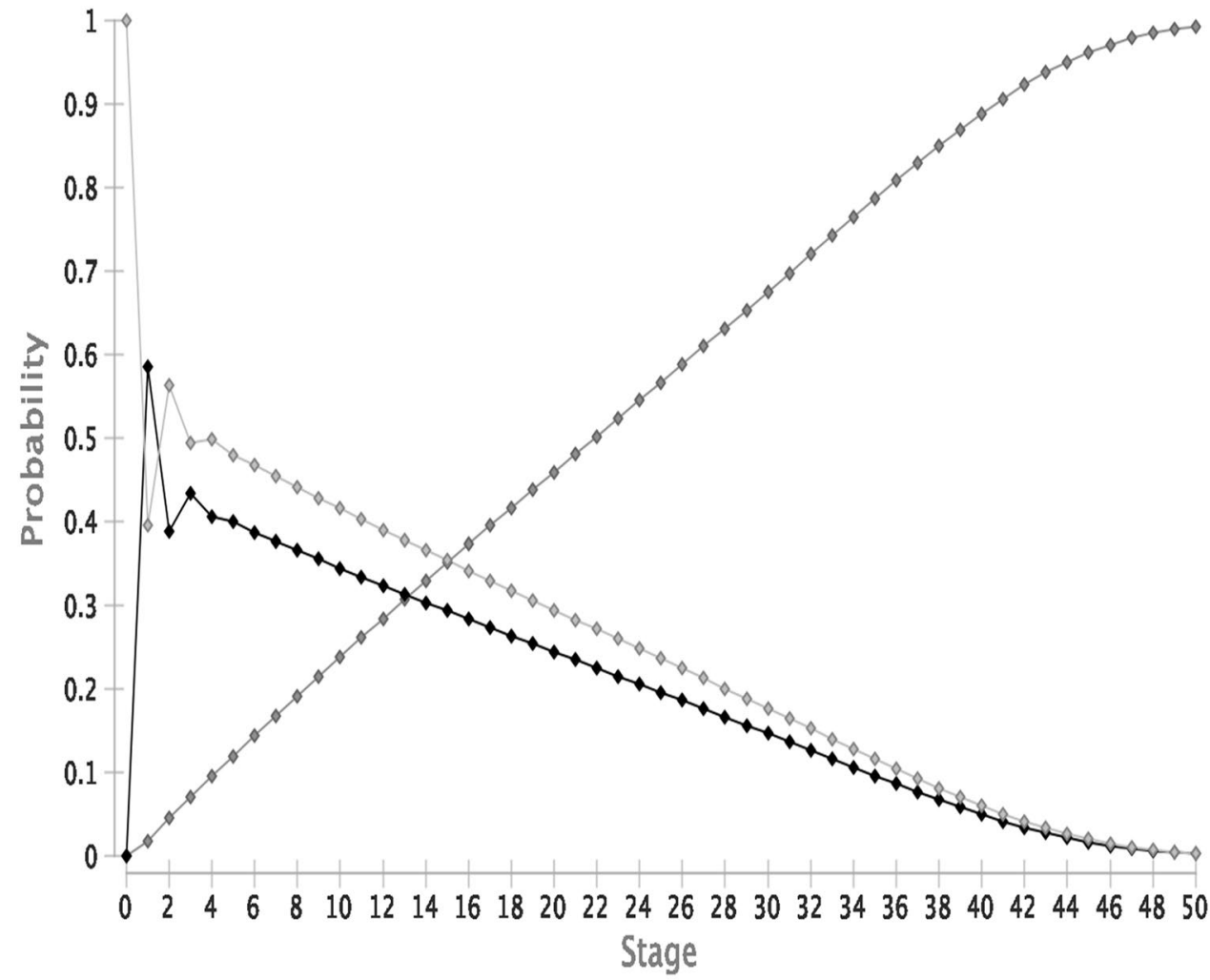

Dead

Moderate to Severe Depression $\checkmark$ No or Mild Depression to mild depression state, $56.4 \%$ were now in the no to mild depression state, $38.9 \%$ were in the moderate to severe depression state, and the cumulative death rate rises to $4.7 \%$. After 25 cycles, only $43.3 \%$ of the cohort are still alive, being the proportion of individuals with no to mild depression higher than those in the moderate to severe depression cohort; the cumulative death rate is $56.7 \%$. By the end of the 50 th cycle, $<0.7 \%$ of the initial cohort remain alive. The medical + behavioral cumulative cost was $\$ 762,135$ and the cumulative effectiveness was 1119.6 QALYs. Because our initial depression rate was high, and in the absence of behavioral care, a sizable share of the subjects would have transited to the depressive state and died due to AIDS-related or depression-related conditions. The provision of integrated treatment allowed some to recover within 1 year and go back to a mild depression state, however some patients relapsed.

\subsection{Sensitivity Analysis: Deterministic (DSA) and Probabilistic (PSA)}

As there are several sources of parameter uncertainty, we ran sensitivity analyses with 1000 iterations to fathom how variations in the input parameters (cost, effectiveness, or probabilities) impacted the results (ICER or NMB). Sensitivity analyses accounted for uncertainty in estimating the parameter and around the model's assumptions. We choose a range of probability values while keeping the remainder of the variables constant. We varied the baseline probability and utility estimate values to probe whether the results changed given the parameters $[64,65]$, addressing the unpredictability of health states $[66,67]$. These values were compared with the outputs, considering a WTP of $\$ 50,000$ per QALY.

\subsection{DSA}

The one-way sensitivity analysis illustrated in Fig. 4 shows the positive relationship between pImprove and NMB (monetary value of the intervention given the WTP for a unit of benefit) for those who received mental health treatment, measuring the efficacy of the medical + behavioral strategy. Likewise, when pImprove increases, the ICER, or the cost of an additional unit of perfect health (dollar value of QALY), tends to decline. For pDieAIDSDep, both the monetary value of the intervention and the per QALY cost decline. Figure 5 illustrates that as QALYs increase, the NMBs rise and the medical-only strategy is only cost effective below 41.45 QALYs, but, above that point, the medical + behavioral strategy becomes cost effective, confirming that our utility values are within the right boundaries. These graphs also indicate that as the number of QALYs increase for OAWH who are severely depressed, the medical + behavioral strategy has limited benefits and 
(a) NMB vs pImprove

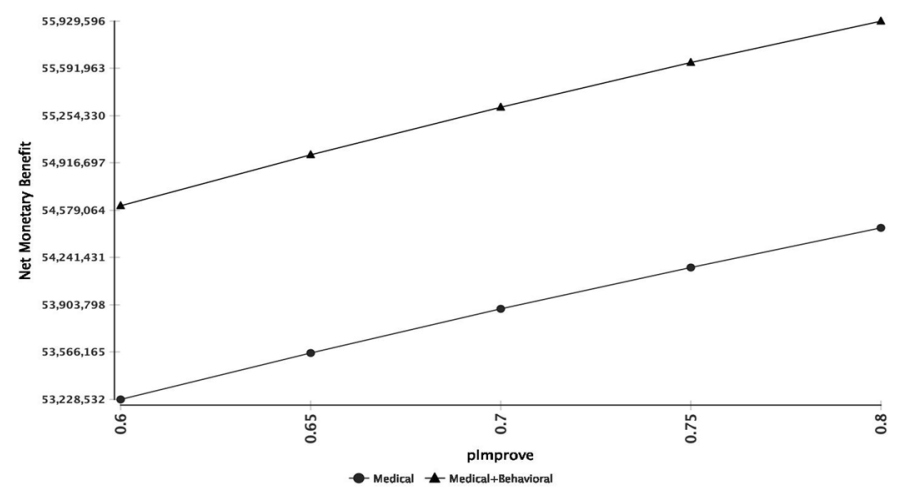

(c) NMB vs pDieAIDSDep

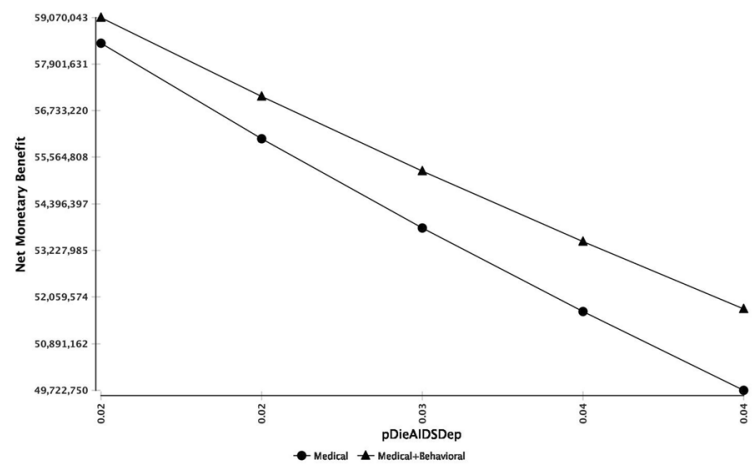

Fig. 4 One-way sensitivity analysis-pImprove and pDieAIDSDep (WTP $=\$ 50,000)$. pImprove is the share of OAWH who recover from depression due to mental health care, and pDieAIDSDep is the share of OAWH who die due to HIV/AIDS and depression-related condi-

stops being cost effective up to 61.8 QALYs; however, after this point, the medical-only strategy becomes cost effective. The tornado diagram shown in Fig. 6 specifies that changes in HIV/AIDS and depression-related mortality have the greatest effect on outcome, while variations in the cost of HIV care have relatively small effects on outcome.

\subsection{PSA}

We conducted a PSA to inspect the effects of several input variables on outputs at the same time. A beta distribution was used for probabilities, which are bounded between 0 and 1, while a log-normal distribution was used for the costs where the support of the distribution is from zero to infinity. We used a Monte Carlo simulation technique with 1000 samples and repeated the process several times to ensure that the values were stable enough. From the original model, we (b) ICER vs pImprove

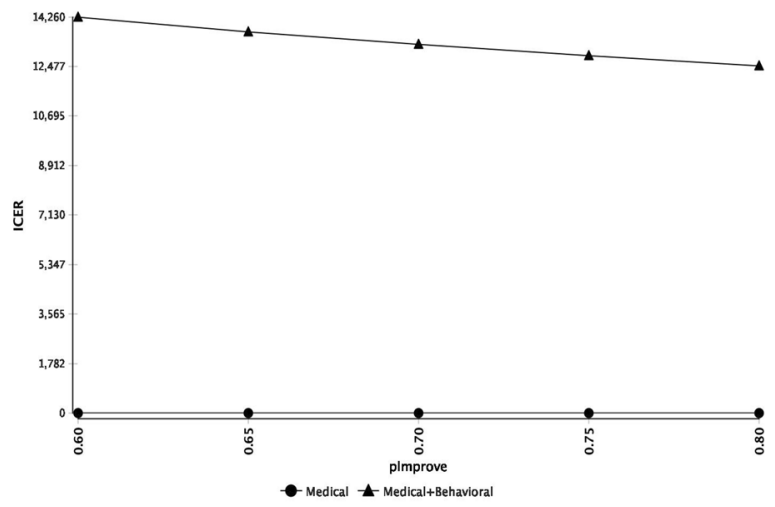

(d) ICER vs pDieAIDSDep

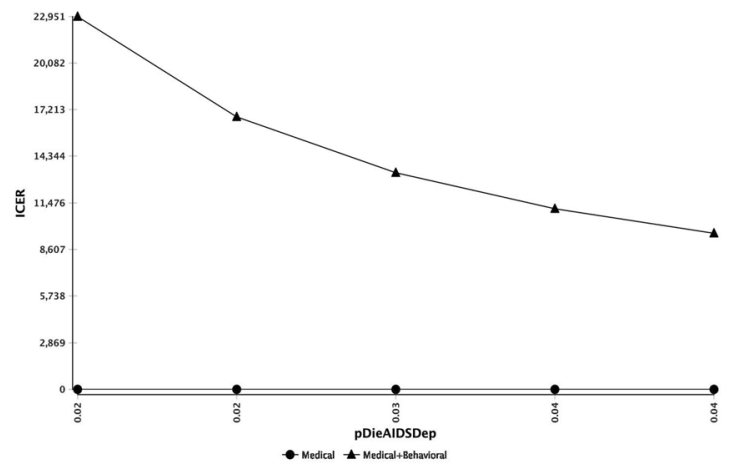

tions, excluding background mortality. WTP willingness to pay, $O A W H$ older adults with HIV, ICER incremental cost-effectiveness ratio, $N M B$ net monetary benefit

transformed the parameters into distributions to confirm, or not, our base case [55, 68-71]. In the original model, we defined the medical + behavioral strategy as cost effective, however this result provides a moderate but not overwhelming confidence because the result was based on a predetermined parameter. Our PSA output was similar to the base case and confirms that the medical + behavioral strategy is cost effective. Table $3 \mathrm{~b}$ shows the cost-effectiveness rankings, with results confirming those of the original model, with an ICER higher in the probabilistic analysis $(\$ 22,946)$ compared with the base model $(\$ 13,315)$. Figure 7 introduced the cost-effectiveness acceptability curve (CEAC) to establish that at the bottom of the WTP threshold range ( $<\$ 29,000$ per QALY), the medical-only strategy has the highest probability of being cost effective. The CEAC indicates that for a WTP $>\$ 29,000$ per QALY, the medical + behavioral strategy has the highest probability of being cost effective compared with the alternative. When the WTP 
(a) NMB vs effMildDepress

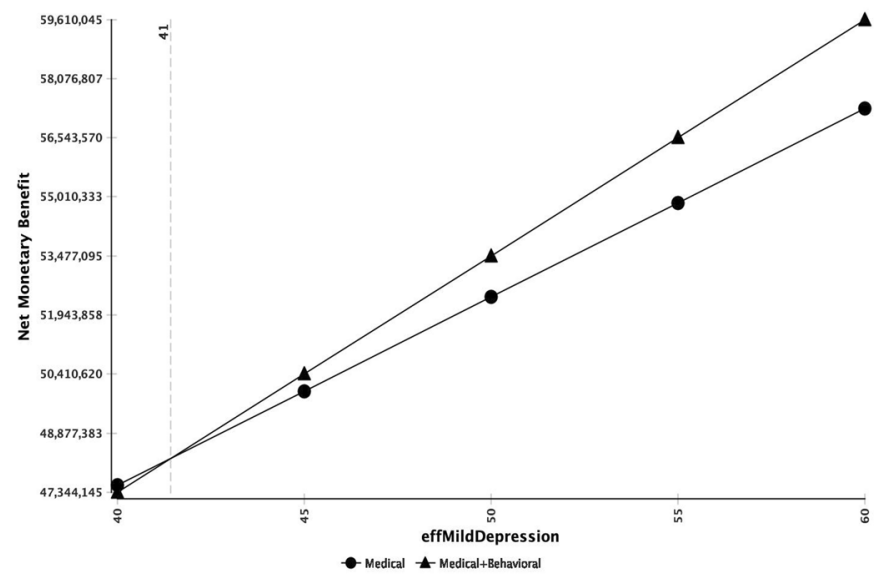

(c) NMB vs effSevereDepress

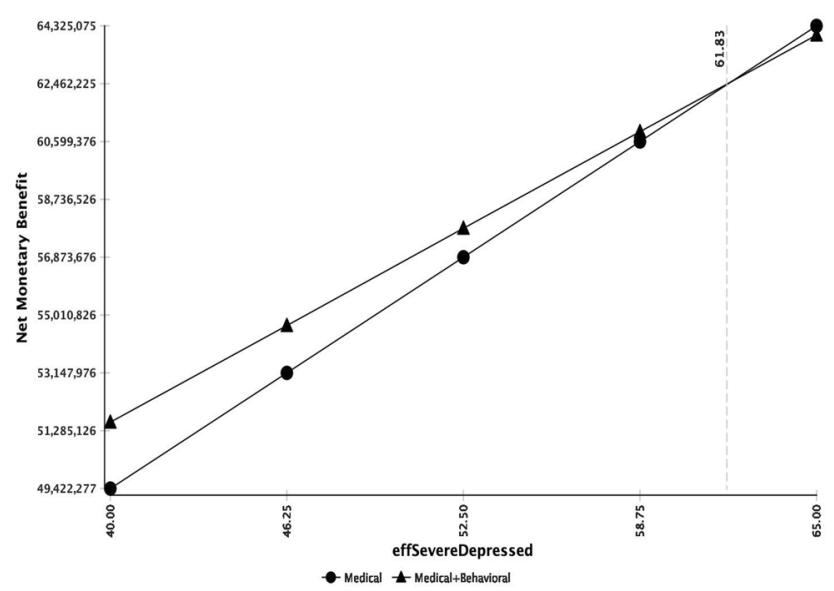

Fig. 5 One-way sensitivity analysis-effMildDepress and effSevereDepress $(\mathrm{WTP}=\$ 50,000)$. Proxies for treatment effectiveness describing the utility of being mildly depressed (effMildDepress) and

was $\$ 50,000$, the medical + behavioral strategy was chosen $68.8 \%$ of the time, but at $\$ 100,000$, the likelihood of selecting the medical + behavioral strategy would be $81.7 \%$. Figure 8 introduces the incremental cost-effectiveness scatter plot displaying the likelihood that our medical + behavioral treatment could be chosen, with the share of points within the scatter plot falling to the east and south of the WTP line, with the slope passing through the origin [72]. We confirmed that $68.8 \%$ of the points lie to the right of the WTP ray, thus make our strategy a superior choice compared with the medical-only strategy. (b) ICER vs effMildDepress

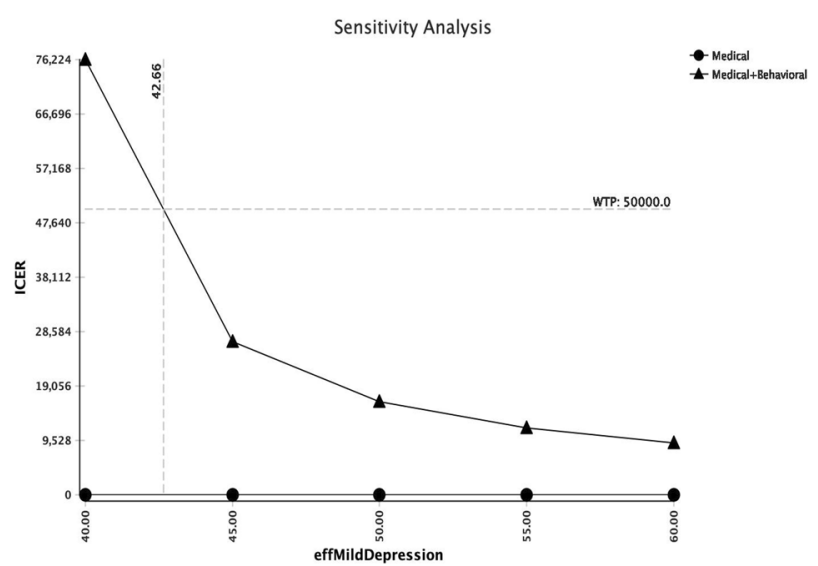

(d) ICER vs effSevereDepress

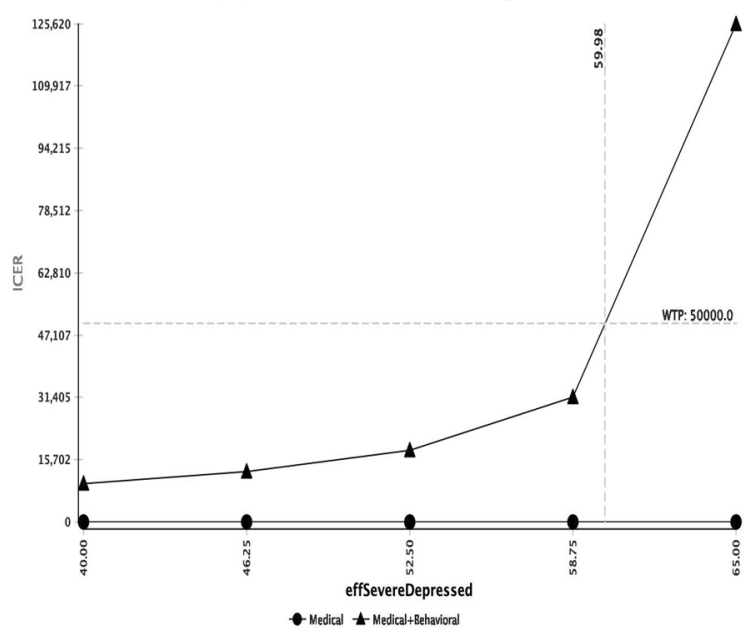

severely depressed (effSevereDepress), both measured in QALYs. $W T P$ willingness to pay, $Q A L Y s$ quality-adjusted life-years, $N M B$ net monetary benefit, ICER incremental cost-effectiveness ratio

\section{Discussion}

HIV is multifactorial and requires clinically sound approaches concomitant with innovative mental health and social and legal services to produce cost-effective outcomes. OAWH taking ART are vulnerable to mental health disorders and our sample reported a group of aging people with HIV experiencing an unusually high level of mental health illness, with a substantial share who did not seek treatment. An integrated system is instrumental to significantly reduce the effect of the epidemic and achieve better QoL [73]; this is important because our sample showed high depression 


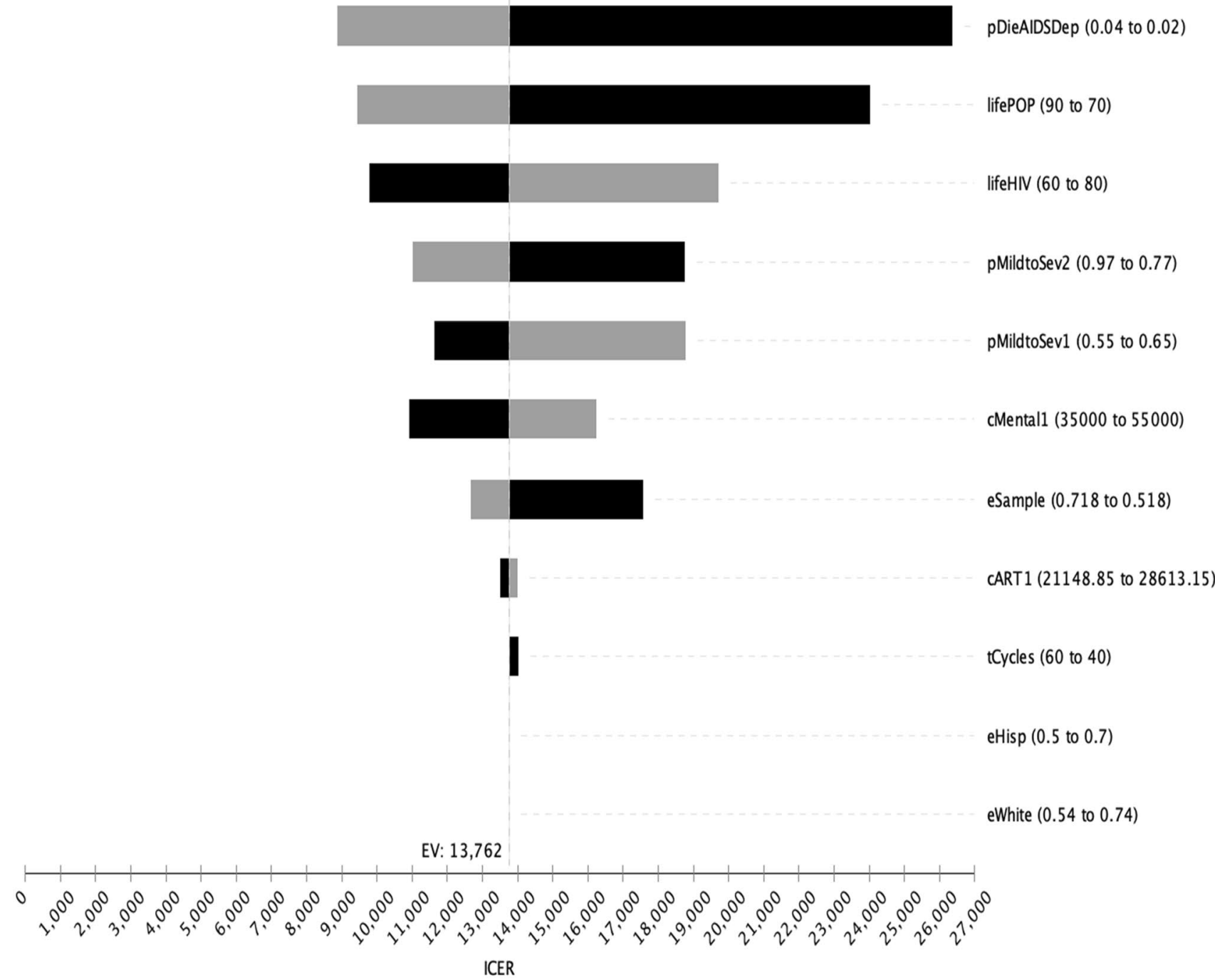

Fig. 6 Tornado diagram-ICER. Medical+behavioral vs. medical (WTP $=\$ 50,000)$. This graph shows how changes in each input variable affect the outcome, and are arranged in decreasing width order. ICER incremental cost-effectiveness ratio, WTP willingness to pay

levels concurrent with substance use and risky sexual behaviors, which is consistent with the literature [74-76]. Depression is a common and usually misdiagnosed medical challenge affecting the lifecycle of OAWH [77-79]; however, unfortunately, OAWH and older Hispanic patients with HIV underutilize mental health services [80, 81]. Moreover, social isolation and loneliness are associated with mental health disorders and predict poor health and an increased likelihood of premature death [82-84]. Psychosocial conditions are both a medical dilemma and an economic conundrum affecting OAWH, and, without family and community support, behavioral illnesses add $\$ 7$ billion to Medicare costs as a result of longer stays in hospitals [85]. Thus, costeffectiveness and cost-saving studies are paramount to better understand the resource allocation of clinical interventions.
We proxied psychosocial factors to predict poor health and survival rates in our sample of OAWH [86]. We recommended mental health integrated to state-of-the-art medical treatment as a cost-effective approach. Although people with HIV/AIDS under ART have a low risk of dying as a result of the infection [87], there is evidence that death rates are higher among people with HIV when compared with the general population [48, 88, 89]. In our model, cumulative mortality was lower for the medical + behavioral strategy compared with the medical-only strategy, suggesting that an integrated system that efficaciously links HIV patients with assorted mental health services produces the largest number of QALYs for the outlay [90]. It is important to recognize that psychological disorders represent a syndemic of behavioral health issues that include depression, loneliness, trauma derived from having HIV, and substance use 


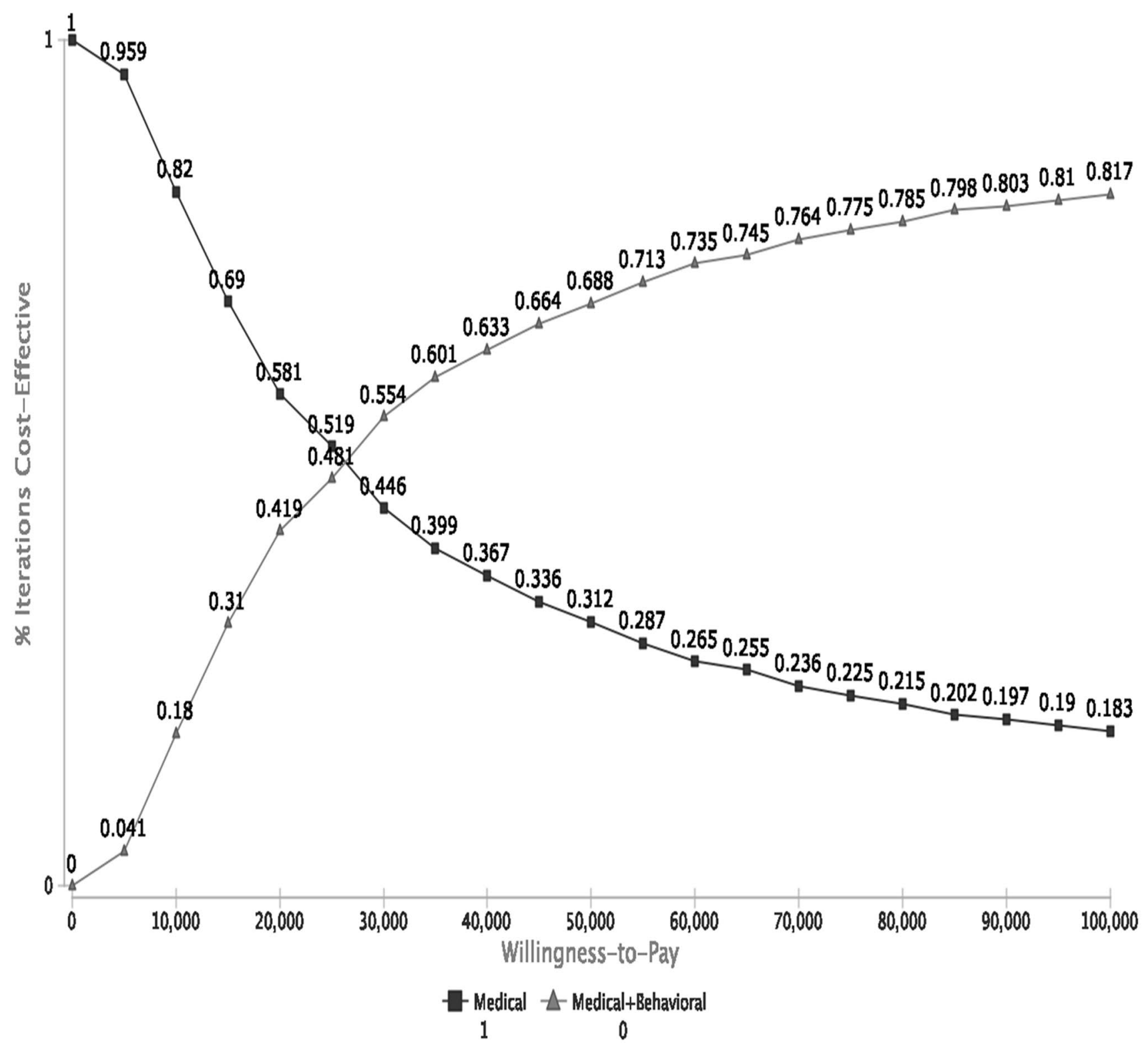

Fig. 7 CEAC (WTP $=\$ 50,000$ ), which was based on 1000 iterations or samples to summarize uncertainty of the estimates. $C E A C$ cost-effectiveness acceptability curve, WTP willingness to pay

[77, 91, 92]. Thus, focusing on these problems in isolation will unlikely resolve contributing factors; for instance, treating depression without acting to reduce social isolation and loneliness that may exacerbate, if not be the root cause of, this condition [93]. Pharmacological treatment of behavioral health problems is the most cost effective, if combined with other therapeutic modalities [94, 95]. Thus, outpatient clinics, community-based programs, and individual face-toface psychotherapy combined with other remedies are at the high-end regarding effectiveness and cost. These costs can be reduced with high efficacy through the use of telemedicine or group therapy [96], with the caveat that technology can also be a source of health disparities. Small and closed groups based on positive psychology principles with elements of psychoeducation and therapeutic effects of group participation have been proven to be effective [97]. An adaptation of the MacArthur Project, with respect to intervention for OAWH, is a low-cost and scalable social support program that, in combination with treatment as usual, halved depressive symptom scores over a 6-month period [98]. These interventions reduce social isolation and promote social interaction through group therapy or weekly phone calls from a care manager. The use of mobile phone technologies offers additional low-cost and high efficacy options for reducing mental health problems in OAWH in resourcepoor areas in Latin America and sub-Saharan Africa [99, 


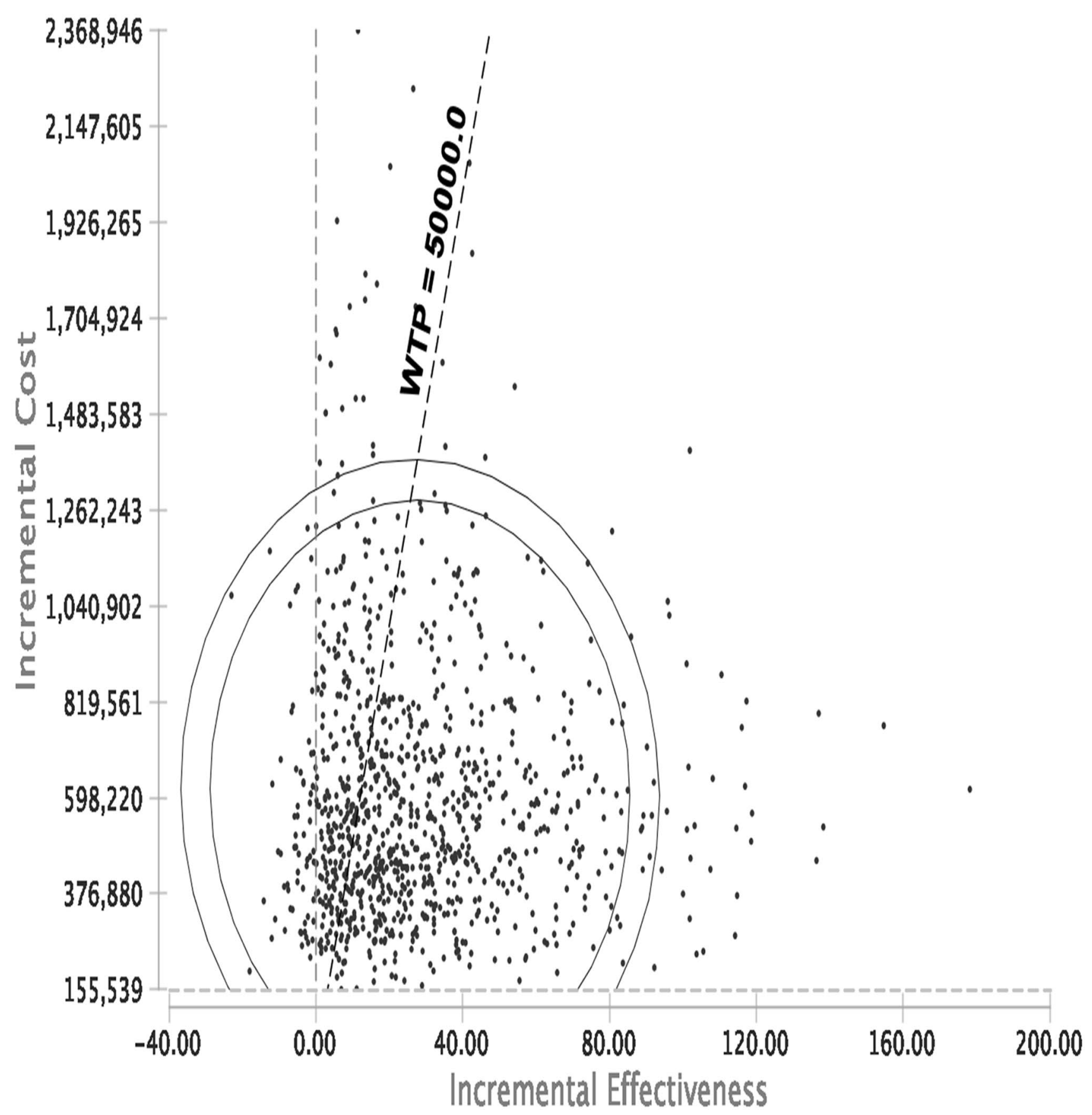

Fig. 8 Scatter plot of incremental cost-effectiveness: medi$\mathrm{cal}+$ behavioral versus medical. This scatter plot identifies the probability that the new treatment is cost effective, where the vertical axis represents the incremental cost, the horizontal axis is the incremental

100], and was particularly effective in reducing social isolation among people with HIV in rural areas. In addition, the trauma-informed peer support for people living with HIV can be cost effective [101]. Thus, mental health interventions that are able to address the multifaceted causes of psychological distress among OAWH can be highly effective, but are not always high-cost programs. effectiveness, and the ellipses denote $90 \%$ and $95 \%$ confidence intervals. More than $68.8 \%$ of the points lie to the right of the WTP ray, thus make our strategy a superior choice compared with 'medical' only. WTP willingness to pay

The lack of evidence-based cost studies for the gradient of HIV and mental health interventions is a limitation of our study. Furthermore, non-probability samples do not contain all members of a population and carry lower levels of generalization. Time is a crucial parameter of Markov models that facilitates the analysis of chronic diseases, thus future states depend only on the current states and not on 
the path followed in the past [102]. This could be restrictive for specific diseases and models with many states. Cohort simulations assume an homogeneous population with constant risk throughout the time horizon. CEAs use refined statistical and standardized procedures and serves as a guide for resource allocation [103]. Markov models are simple and easy to understand for a broader audience but can be contentious because they assign implicit and explicit monetary values on human life, therefore decision makers can use this knowledge to control expenses. CEAs have been extensively used in economic evaluations but seldom discuss issues of fairness and equity. Our findings cannot serve as a substitute for value judgments.

\section{Conclusions}

We determined that an integrated system (medical + behavioral) is cost effective to improve QoL among OAWH. We produced a computer-generated progression of mental health and death to synthesize information using a Markov model based on simple mathematical constructions [104]. As simulated in our model, assuming effective identification of mental health disorders and proper referral to care is key to producing better health outcomes. Our findings inform how resource allocation can improve health outcomes based on our sample results. Policy makers need to prioritize the share of people virally suppressed with the addition of mental health care in the midst of the 'graying' of the epidemic.

\section{Declarations}

Funding This study was supported by the HISTP from the Columbia University's School of Social Work, a National Institute of Mental Health-funded program.

Conflicts of interest/competing interests Juan J. DelaCruz, Mark Brennan-Ing, Andreas Kakolyris, and Omar Martinez do not have any conflicts of interest to declare.

Ethics approval We received Institutional Review Board approval (IRB File\#2017-0857) from the City University of New York for the use of human subjects.

Consent to participate A consent form to voluntarily participate was collected from every participant in the study.

Consent for publication All co-authors made substantial contributions to the paper and have approved the final version submitted. All authors have agreed on the authorship of the manuscript and its publication.

Availability of data, code, and material To comply with the initiative of data transparency, we are committed to sharing our data, files, and methods used in this paper. We adhere to our discipline rules for acquiring, selecting, and processing data to the best of our knowledge. TreeAge software was used for decision analysis.
Author contributions Juan J. DelaCruz: Conceptualization, funding acquisition, methodology, data curation, formal analysis, writing of the manuscript (original draft, review, and final version), and visualization. Mark Brennan-Ing: Conceptualization, expertise in HIV, older adults and behavioral interventions; writing of the manuscript (original draft and review). Andreas Kakolyris: Conceptualization, methodology, formal analysis, and writing of the manuscript (original draft, review, and final version). Omar Martinez: Conceptualization, expertise in HIV and underserved communities, and writing of the manuscript (original draft and review).

Open Access This article is licensed under a Creative Commons Attribution-NonCommercial 4.0 International License, which permits any non-commercial use, sharing, adaptation, distribution and reproduction in any medium or format, as long as you give appropriate credit to the original author(s) and the source, provide a link to the Creative Commons licence, and indicate if changes were made. The images or other third party material in this article are included in the article's Creative Commons licence, unless indicated otherwise in a credit line to the material. If material is not included in the article's Creative Commons licence and your intended use is not permitted by statutory regulation or exceeds the permitted use, you will need to obtain permission directly from the copyright holder. To view a copy of this licence, visit http://creativecommons.org/licenses/by-nc/4.0/.

\section{References}

1. Wing EJ. The aging population with HIV. Trans Am Clin Climatol Assoc. 2017;128:131-44.

2. Agus DF, Effendy E, Camellia V. Screening of anxiety and depression related CD4 count of people living with HIV/AIDS with anti-retroviral in Medan, Indonesia. Open Access Maced J Med Sci. 2019;7(16):2590-4. https://doi.org/10.3889/oamjm s.2019.396.

3. Wandeler G, Johnson LF, Egger M. Trends in life expectancy of HIV-positive adults on antiretroviral therapy across the globe: comparisons with general population. Curr Opin HIV/AIDS. 2016;11(5):492-500. https://doi.org/10.1097/COH.0000000000 000298 .

4. Xiao Y, Sun X, Tang S. Personalized life expectancy and treatment benefit index of antiretroviral therapy. Theor Biol Med Model. 2017;14(1):1. https://doi.org/10.1186/s1297 6-016-0047-0.

5. Auclair M, Guénantin AC, Fellahi S, et al. HIV antiretroviral drugs, dolutegravir, maraviroc and ritonavir-boosted atazanavir use different pathways to affect inflammation, senescence and insulin sensitivity in human coronary endothelial cells PLoS One. 2020;15(1):e0226924. https://doi.org/10.1371/journ al.pone.0226924.

6. Mann SC, Carrillo-Mancilla JR. HIV, aging, and adherence: an update and future directions. Curr Opin HIV AIDS. 2020;15(2):134-41. https://doi.org/10.1097/COH.0000000000 000615 .

7. Schouten J, Wit FW, Stolte IG, et al. Cross-sectional comparison of the prevalence of age-associated comorbidities and their risk factors between HIV-infected and uninfected individuals: the AGEhIV Cohort study. Clin Infect Disease. 2014;59(12):1787-97.

8. Freedman SF, Johnston C, Faragon JJ. Older HIV-infected adults. Complex patients (III): Polypharmacy. Eur Geriatr Med. 2019;10(2):199-211. https://doi.org/10.1007/s4199 9-018-0139-y. 
9. Xiong GL, Iosif AM, Suo S, et al. Understanding preventive health screening services use in persons with serious mental illness: how does integrated behavioral health primary care compare? Int J Psychiatry Med. 2015;48(4):279-98.

10. Clifford DB, Ances BM. HIV-associated neurocognitive disorder (HAND). Lancet Infect Dis. 2013;13(11):976-86. https://doi. org/10.1016/S1473-3099(13)70269-X.

11. Milanini B, Valcour V. Differentiating HIV-associated neurocognitive disorder from Alzheimer's disease: an emerging issue in geriatric neuro HIV. Curr HIV/AIDS Rep. 2017;14(4):123-32. https://doi.org/10.1007/s11904-017-0361-0.

12. Agarwal R, Aujla RS, Gupta A, Kumar M. Determining the neurocognitive status and the functional ability of patients to screen for HIV-associated neurocognitive disorder (HAND). Dement Neurocogn Disord. 2020;19(1):19-27. https://doi. org/10.12779/dnd.2020.19.1.19.

13. Fox HA. The natural course of depression: kraepelin and beyond. Harvard Rev Psychiatry. 2002;10(4):249-53.

14. Kessler RC, Berglund PA, Bruce ML, et al. The prevalence and correlates of untreated serious mental illness. Health Serv Res. 2001;36(6 Pt 1):987-1007.

15. López E, Steiner AJ, Manier K, et al. Quality of life and functioning of hispanic patients with major depressive disorder before and after treatment. J Affect Disord. 2008;225:117-22. https://doi.org/10.1016/j.jad.2017.08.031.

16. Terloyeva D, Nugmanova Z, Akhmetova G, et al. Untreated depression among persons living with human immunodeficiency virus in Kazakhstan: a cross-sectional study. PLoS One. 2008;13(3):e0193976. https://doi.org/10.1371/journ al.pone. 0193976 .

17. Wang T, Fu H, Kaminga AC, et al. Prevalence of depression or depressive symptoms among people living with HIV/AIDS in China: a systematic review and meta-analysis. BMC Psychiatry. 2018;18:160. https://doi.org/10.1186/s12888-018-1741-8.

18. Van den Berg M, Smit F, Vos T, Van Baal. Cost-effectiveness of opportunistic screening and minimal contact psychotherapy to prevent depression in primary care patients. PLoS One. 2011;6(8):e22884. https://doi.org/10.1371/journal.pone.00228 84.

19. Jivraj S, Nazroo J, Barnes M. Short- and long-term determinants of social detachment in later life. Ageing Soc. 2016;36:924-45. https://doi.org/10.1017/S0144686X140015 61.

20. Korthuis PT, et al. Quality of HIV care and mortality rates in HIV-infected patients. Clin Infect Dis. 2016;62(2):233-9. https ://doi.org/10.1093/cid/civ762.

21. Simon J, Pilling S, Burbeck R, Goldberg D. Treatment options in moderate and severe depression: decision analysis supporting a clinical guideline. Br J Psychiatry. 2006;189:494-501. https:// doi.org/10.1192/bjp.bp.105.014571.

22. Brennan-Ing M, Seidel Liz, Geddes L, et al. Adapting a telephone support intervention to address depression in older adults with HIV. J HIV/AIDS Soc Serv. 2017;16(4):335-350. https://doi. org/10.1080/15381501.2017.1318103.

23. Samhkaniyan E, Mahdavi A, Mohamadpour S, et al. The effectiveness of mindfulness-based cognitive therapy on quality of life and loneliness of women with HIV. J Med Life. 2015;8(Spec Iss 4):107-113

24. Käll A, Jägholm S, Hesser H, et al. Internet-based cognitive behavior therapy for loneliness: a pilot randomized controlled trial. Behav Ther. 2019;51(1):54-68. https://doi.org/10.1016/j. beth.2019.05.001.

25. Chibanda D. Depression and HIV: integrated care towards 90-9090. Int Health. 2017;9(2):77-9. https://doi.org/10.1093/inthealth/ ihw058.
26. Chuah FLH, Haldane VE, Cervero-Liceras F, et al. Interventions and approaches to integrating HIV and mental health services: a systematic review. Health Policy Plan. 2017; 32 Suppl 4:iv27iv47. https://doi.org/10.1093/heapol/czw169.

27. Maulsby C, Jain KM, Weir BW, et al. Cost-utility of access to care, a national HIV linkage, re-engagement and retention in care program. AIDS Behav. 2018;22(11):3734-41. https://doi. org/10.1007/s10461-017-2015-z.

28. Flash MJE, Garland WH, Martey EB, et al. Cost-effectiveness of a medical care coordination program for people with HIV in Los Angeles County. Open Forum Infect Dis. 2019;6(12):ofz537. https://doi.org/10.1093/ofid/ofz537.

29. Stevens ER, Nucifora KA, Irvine MK, et al. Cost-effectiveness of HIV care coordination scale-up among persons at high risk for suboptimal HIV care outcomes. PLoS One. 2019;14(4):e0215965. https://doi.org/10.1371/journ al.pone. 0215965 .

30. Painter JT, Fortney JC, Gifford AL, et al. Cost-effectiveness of collaborative care for depression. J AIDS. 2015;70(4):377-85. https://doi.org/10.1097/QAI.0000000000000732.

31. Nakimuli-Mpungu E, Musisi S, Wamala K, et al. Effectiveness and cost-effectiveness of group support therapy delivered by trained lay health workers for depression treatment among people with HIV in Uganda: a cluster-randomised trial. Lancet Glob health. 2020;8(3):e387-98. https://doi.org/10.1016/S2214 -109X(19)30548-0.

32. American Psychological Association. National HIV/AIDS and Aging Awareness Day. https://www.apa.org/pi/aids/resources/ aging-awareness. Accessed 25 Apr 2020.

33. HIV Intervention Science Training Program for Underrepresented New Investigators at the Columbia's School of Social Work (sponsored by the National Institute of Mental Health). https://histp.columbia.edu.

34. McCabe C, Brazier J, Gilks P, et al. Using rank data to estimate health state utility models. J Health Econ. 2006;25(3):418-31. https://doi.org/10.1016/j.jhealeco.2005.07.008.

35. Kharroubi S, Brazier JE, Roberts JR, O'Hagan A. Modelling SF-6D health state preference data using a nonparametric bayesian method. J Health Econ. 2007;26(3):597-612. https://doi. org/10.1016/j.jhealeco.2006.09.002.

36. Brazier J, Roberts J, Deverill M. The Estimation a preferencebased single index measure for health from the SF-36. J Health Econ. 2002;21(2):271-92. https://doi.org/10.1016/s0167 $-6296(01) 00130-8$.

37. Samji H, Cescon A, Hogg RS, et al. Closing the gap: increases in life expectancy among treated HIV-positive individuals in the United States and Canada. PLoS One. 2013;8(12):e81355. https ://doi.org/10.1371/journal.pone.0081355.

38. The World Bank-Data. https://data.worldbank.org/country/unite d-states. Accessed 10 Mar 2020.

39. TreeAge Pro 2020, R1.1. Williamstown, MA: TreeAge Software. http://www.treeage.com).

40. Sonnenberg FA, Beck JR. Markov models in medical decision making: a practical guide. Med Decis Making. 1993;13(4):322-38.

41. Radloff LS. The CED-D scale: a self-report depression scale for research in the general population. Appl Psychol Meas. 1977;1:385-401.

42. Hann D, Winter K, Jacobsen P. Measurement of depressive symptoms in cancer patients: evaluation of the center for epidemiological studies depression scale (CES-D). J Psychosom Res. 1999;46(5):437-43. https://doi.org/10.1016/s0022 -3999(99)00004-5.

43. Nizami S, Morales $\mathrm{C}, \mathrm{Hu} \mathrm{K}$, et al. Trends in mortality from human immuno-deficiency virus infection, 1984-2016: an 
autopsy-based study. Arch Pathol Lab Med. 2020;144(5):572-9. https://doi.org/10.5858/arpa.2019-0144-OA.

44. Verheul HA, Dekker P, Bossuyt AC, et al. Background mortality in clinical survival studies. Lancet. 1993;341(8849):872-5. https ://doi.org/10.1016/0140-6736(93)93073-a.

45. Torrance GW. Measurements of health state utilities for economic appraisal. J Health Econ. 1986;5(1):1-30. https://doi. org/10.1016/0167-6296(86)90020-2.

46. Bhatia MS, Munjal S. Prevalence of depression in people with HIV/AIDS undergoing ART and factors associate with it. J Clin Diagn Res. 2014;8(10):WC01-WC04. https://doi.org/10.7860/ jcdr/2014/7725.4927.

47. Del Amo J, Jarrin I. All-cause mortality after ART initiation in HIV-positive women from Europe, Sub-Saharan Africa and the Americas. AIDS. 2020;34(2):277-89. https://doi.org/10.1097/ QAD.0000000000002399.

48. Prince PD, Matser A, Van Tienen C, et al. Mortality rates in people dually infected with HIV-1/2 and those infected with either HIV-1 or HIV-2: a systematic review and meta-analysis. AIDS. 2014;28(4):549-58. https://doi.org/10.1097/01.SPC.0000432532 .87841 .78 .

49. Hanna DB, et al. Trends in cardiovascular disease mortality among persons with HIV in NYC, 2001-2012. Clin Infect Dis. 2016;63(8):1122-9. https://doi.org/10.1093/cid/ciw470.

50. Dawood H, et al. Mortality and treatment response amongst HIVinfected patients 50 years and older accessing antiretroviral services in South Africa. BMC Infect Dis. 2018;18(168):1-9. https ://doi.org/10.1186/s12879-018-3083-z.

51. US Department of Health \& Human Services. https://www.hiv. gov/hiv-basics/overview/data-and-trends/statistics. Accessed 1 Feb 2020.

52. Nguyen N, Holodniy M. HIV infection in the ederly. Clin Interv Aging. 2008;3(3):453-72. https://doi.org/10.2147/cia.s2086.

53. Keller MB, Lavori PW, Mueller TI, et al. Time to recovery, chronicity, and levels of psychopathology in major depression. a 5-year prospective follow-up of 431 subjects. Arch Gen Psychiatry. 1992;49(10):809-16. https://doi.org/10.1001/archp syc.1992.01820100053010.

54. Arias E, Xu JQ. United States Life Tables, 2017. National Vital Statistics Reports. 2019;68(7). National Center for Health Statistics. Available at: https://www.cdc.gov/nchs/products/life_table s.htm.

55. Garrison LP, Pauly. MV, Wilke JJ, et al. An overview value, perspective and decision context-a health economics approach: an ISPOR special task force report. Value Health. 2018;21(2):124130. https://doi.org/10.1016/j.val.2017.12.006.

56. Gebo KA, Fleishman JA, Conviser R, et al. Contemporary costs of HIV health care in the HAART era. AIDS. 2010;24(17):270515. https://doi.org/10.1097/QAD.0b013e32833f3c14.

57. Centers for Disease Control and Prevention. HIV cost-effectiveness. https://www.cdc.gov/hiv/programresources/guidance/coste ffectiveness/index.html. Accessed 10 Feb 2020.

58. Weaver MR, Conover CJ, Proescholdbell RJ, et al. Cost-effectiveness analysis of integrated care for people with HIV, chronic mental illness and substance abuse disorders. J Ment Health Policy Econ. 2009;12(1):33-46.

59. Gordon C. Economic benefits of active transportation. In: Larouche R (ed). Children's active transportation. Elsevier; 2018. p. 306. https://doi.org/10.1016/C2016-0-01988-5.

60. Tran BX, Vu GT, Nguyen THT, et al. Demand and willingness to pay for different treatment and care services among patients with heart diseases in Hanoi, Vietnam. Patient Prefer Adher. 2018;2018:2253-61. https://doi.org/10.2147/PPA.S176262.
61. Gafni A. Willingness to pay in the context of an economic evaluation of healthcare programs: theory and practice. Am J Manag Care. 1997;3(Suppl):S21-32.

62. Neumann PJ, Weinstein MC. Legislating against use of costeffectiveness information. N Engl J Med. 2010;363:1495-7. https ://doi.org/10.1056/NEJMp1007168.

63. US Bureau of Labor Statistics. CPI Inflation Calculator. Washington, DC: US Bureau of Labor Statistics. http://www.bls.gov/ data/inflation_calculator.htm. Accessed 6 Jun 2020.

64. Doubilet P, Begg CB, Weinstein MC, et al. Probabilistic sensitivity analysis using monte carlo simulation. a practical approach. Med Decis Making. 1985;5(2):157-77. https://doi. org/10.1177/0272989x8500500205.

65. Sanders GD, Bayoumi AM, Holodniy M, et al. Cost-effectiveness of HIV screening in patients older than 55 years of age. Ann Intern Med. 2008;148:889-903.

66. Zhang Y, Wu H, Denton BT, et al. Probabilistic sensitivity analysis on markov models with uncertain transition probabilities: an application in evaluating treatment decision for type 2 diabetes. Health Care Manag Sci. 2019;22:34-52. https://doi.org/10.1007/ s10729-017-9420-8.

67. Geisler BP, Sieber U, Gazelle GS, et al. Deterministic sensitivity analysis for first-order monte carlo simulations: a technical note. Value Health. 2009;12(1):96-7.

68. Briggs AH. Handling uncertainty in cost-effectiveness models. Pharmacoeconomics. 2000;17(5):479-500.

69. Baio G, Dawid AP. Probabilistic sensitivity analysis in health economics. Stat Methods Med Res. 2015;24(6):615-34. https:// doi.org/10.1177/0962280211419832.

70. Guarin-Tellez NE, Moreno Calderón JA, Muñoz-Galindo IM, et al. Cost-effectiveness of a care program for HIV/AIDS patients affiliated with a health insurer in colombia, comparing three health care providers nationwide. Value Health Reg Issues. 2015;11C:1-8. https://doi.org/10.1016/j.vhri.2015.11.001.

71. Critchfield GC, Willard KE, Connelly DP. Probabilistic sensitivity analysis for general decision models. Comput Biomed Res. 1986;19:254-65. https://doi.org/10.1016/0010-4809(86)90020 $-0$.

72. Fenwick E, et al. Using and interpreting cost-effectiveness acceptability curves: an example using data from a trial of management strategies for atrial fibrillation. BMC Health Serv. 2006;6:52. https://doi.org/10.1186/1472-6963-6-52.

73. US Department of Health and Human Services (HHS). National HIV/AIDS Strategy for the United States: Updated to 2020 (2017 Progress Report). US Dpeartment of Health and Human Services.

74. Gonzalez JS, Batchelder AW, Psaros C, et al. Depression and HIV/AIDS treatment nonadherence: a review and meta-analysis. J Acquir Immune Defic Syndrome. 2013. https://doi.org/10.1097/ qai.0b013e31822d490a.

75. Hutton HE, Lyketsos CG, Zenilman JM, et al. Depression and HIV risk behaviors among patients in a sexually transmitted disease clinic. Am J Psychiatry. 2004;161(5):912-4. https://doi. org/10.1176/appi.ajp.161.5.912.

76. Effendy E, Amin MM, De Vega L, et al. The association between CD-4 level, stress and depression symptoms among people living with HIV/AIDS. Open Access Maced J Med Sci. 2019;7(20):3459-63. https://doi.org/10.3889/oamjms.2019.446.

77. Grov C, et al. Loneliness and HIV-related stigma explain depression among older HIV-positive adults. AIDS Care. 2010;22(5):630-9. https://doi.org/10.1080/09540120903280901.

78. Nanni MG, et al. Depression in HIV infected patients: a review. Curr Psychiatry Rep. 2015;17(1):530. https://doi.org/10.1007/ s11920-014-0530-4. 
79. Bhatia MS, Munjal S. Prevalence of depression in people living with HIV/AIDS undergoing ART and factors associated with it. journal of clinical and diagnostic research. 2014;8(10):WC01WC04. https://doi.org/10.7860/jcdr/2014/7725.4927.

80. Reif S, Whetten K, Ostermanan J, et al. Psychosocial and sociomedical aspect of HIV/AIDS. AIDS Care. 2006;18(Supp 1):107. https://doi.org/10.1080/09540120600838738.

81. LaVeist TA, Isaac LA, Williams KP. Mistrust of health care organizations is associated with underutilization of health services. Health Serv Res. 2009;44(6):2093-105. https://doi.org/1 0.1111/j.1475-6773.2009.01017.x.

82. Cacioppo JT, Cacioppo S. The growing problem of loneliness. Lancet. 2018;391(10119):426. https://doi.org/10.1016/S0140 $-6736(18) 30142-9$

83. Greene ML, Tan JY, Weiser SD, et al. Patient and provider perceptions of a comprehensive care program for HIV-positive adults over 50 years of age: the formation of the golden compass HIV and aging care program in San Francisco. PLoS One. 2018;13(12):e0208486. https://doi.org/10.1371/journ al.pone. 0208486 .

84. Greene M, Hessol NA, Perissinotto C, et al. Loneliness in older adults living with HIV. AIDS Behav. 2018;22(5):1475-84. https ://doi.org/10.1007/s10461-017-1985-1.

85. AARP. Medicare Spends More on Socially Isolated Older Adults. 2017. https://www.aarp.org/ppi/info-2017/medicare-spend s-more-on-socially-isolated-older-adults.html.

86. Ogburn DF, Schoenbach VJ, Edmonds A, et al. Depression, ART adherence, and receipt of case management services by adults with HIV in North Carolina, Medical Monitoring Project, 2009-2013. AIDS Behav. 2019;23(4):1004-15. https://doi. org/10.1007/s10461-018-2365-1.

87. Croxford S, Kitching A, Desai S, et al. Mortality and causes of death in people diagnosed with HIV in the era of highly active antiretroviral therapy compared with the general population: an analysis of a national observational cohort. Lancet Public Health. 2017;2(1):e35-46. https://doi.org/10.1016/S2468 -2667(16)30020-2.

88. Lucas S, Nelson AM. HIV and the spectrum of human disease. J Pathol. 2015;235:229-41. https://doi.org/10.1002/path.4449.

89. Nishijima T, Inaba Y, Kawasaki Y, et al. Mortality and causes of death in people living with HIV in the era of combination antiretroviral therapy compared with the general population in Japan. AIDS. 2020;34(6):913-21. https://doi.org/10.1097/QAD.00000 00000002498.

90. Brent RJ, Brennan M, Karpiak SE. Economic evaluations of HIV prevention in rich countries and the need to focus on the aging of the HIV-positive population. Curr Opin HV AIDS. 2010;5:25560. https://doi.org/10.1097/COH.0b013e3283384a88.

91. Storholm ED, Halkitis PN, Kupprat SA, et al. HIV-related stigma as a mediator of the relation between multiple-minority status and mental health burden in an aging HIV-positive population. $\mathrm{J}$ HIV/AIDS Soc Serv. 2013;12(1):9-25.

92. Brennan-Ing M, Seidel L, Karpiak SE. Social support systems and social network characteristics of older adults with HIV. In: Brennan-Ing M, DeMarco RF (eds). HIV and Aging. Vol. 42. Karger Publishers; 2017. pp. 159-172.

93. Brennan-Ing M, Seidel L, Geddes L, et al. Adapting a telephone support intervention to address depression in older adults with HIV. J HIV/AIDS Soc Serv. 2017;16(4):335-50.

94. Heuzenroeder L, Donnelly M, Haby MH, et al. Cost-effectiveness of psychological and pharmacological interventions for generalized anxiety disorder and panic disorder. Aust N Z J Psychiatry. 2004;38(8):602-12. https://doi.org/10.108 0/j.1440-1614.2004.01423.x.

95. Skapinakis P, Caldwell D, Hollingworth W, et al. A systematic review of the clinical effectiveness and cost-effectiveness of pharmacological and psychological interventions for the management of obsessive-compulsive disorder in children/adolescents and adults. Health Technol Assess. 2016;20(43):1-392. https:// doi.org/10.3310/hta20430.

96. Egede LE, Gebregziabher M, Walker RJ, et al. Trajectory of cost overtime after psychotherapy for depression in older veterans via telemedicine. J Affect Disord. 2017;207:157-62.

97. Carr A, Finnegan L, Griffin E, et al. A randomized controlled trial of the say yes to life (SYTL) positive psychology group psychotherapy program for depression: an interim report. J Contemp Psychother. 2017;47(3):153-61.

98. Brennan-Ing et al., 2017 (op cit).

99. Dean AL, Makin JD, Kydd AS, et al. A pilot study using interactive SMS support groups to prevent mother-to-child HIV transmission in South Africa. J Telemed Telecare. 2012;18(7):399-403.

100. Erzse A, Simpson N. The Effects of a pioneering support group model on perceived social support amongst HIV positive adolescents in South Africa. Paper presented at the AIDS 2016 Conference; 18-22 July 2016: Durban.

101. Sales JM, Swartzendruber A, Phillips AL. Trauma-informed HIV prevention and treatment. Curr HIV/AIDS Rep. 2016;13(6):37482. https://doi.org/10.1007/s11904-016-0337-5.

102. Briggs A, Sculpher M. An introduction to markov modelling for economic evaluation. Pharmacoeconomics. 1998;13(4):397-409.

103. Husereau D, Drummond M, Petrou S, et al. Consolidated health economic evaluation reporting standards (CHEERS) statement. PharmacoEconomics. 2013;31:361-7. https://doi.org/10.1007/ s40273-013-0032-y.

104. Komorowski M, Raffa J Markov models and cost effectiveness analysis: applications in medical research. In: MIT Critical data. Secondary analysis of electronic health records. Cham: Springer; 2016. https://doi.org/10.1007/978-3-319-43742-2_24. 